\title{
Commentary: Just do it?
}

\author{
Stephanie N. Nguyen, MD, a,b \\ Yuichi J. Shimada, MD, MPH, ${ }^{\mathrm{a}, \mathrm{c}}$ \\ Shepard Weiner, MD, ${ }^{\mathrm{a}, \mathrm{c}}$ and \\ Hiroo Takayama, $\mathrm{MD}, \mathrm{PhD}^{\mathrm{a}, \mathrm{b}}$
}

In this issue of the Journal, a group from the Mayo Clinic investigates the impact of early septal reduction therapy (SRT) on survival in patients with obstructive hypertrophic cardiomyopathy (HCM). ${ }^{1}$ Patients who underwent septal myectomy or alcohol septal ablation within 6 months of initial evaluation at the Mayo Clinic (early SRT group, not early in their clinical symptomatology) were compared with those who received only medical management during the initial 6-month period, regardless of whether SRT was performed at a later point. As expected, the early SRT group had more advanced symptoms and more likely failed medical therapy at the time of index evaluation when compared with the early medical treatment group. The authors demonstrated improved survival with early SRT after adjusting for age and comorbidities.

Although current guidelines recommend SRT for patients with persistent symptoms despite maximal medical therapy and significant left ventricular outflow tract obstruction, 2,3 the optimal timing of SRT is uncertain. A previous study showed increased adverse cardiovascular events and disease progression when SRT is delayed more than 5 years from initial diagnosis, despite successful gradient reduction and symptom relief. ${ }^{4}$ The present study sheds additional light on the optimal timing of SRT in patients with symptomatic obstructive HCM.

Although this observation was not the main focus and might be confounded by indication, SRT improved survival compared with medical management in the present study, challenging the current understanding that SRT improves

\footnotetext{
From the ${ }^{\mathrm{a}}$ Hypertrophic Cardiomyopathy Center; ${ }^{\mathrm{b}}$ Division of Cardiac, Thoracic and Vascular Surgery, Department of Surgery, and ${ }^{\mathrm{c}}$ Department of Medicine, Columbia University Irvine Medical Center/NewYork-Presbyterian, New York, NY.

Disclosures: The authors reported no conflicts of interest.

The Journal policy requires editors and reviewers to disclose conflicts of interest and to decline handling or reviewing manuscripts for which they may have a conflict of interest. The editors and reviewers of this article have no conflicts of interest.

Received for publication Oct 23, 2020; revisions received Oct 23, 2020; accepted for publication Oct 23, 2020; available ahead of print Oct 31, 2020.

Address for reprints: Hiroo Takayama, MD, PhD, 177 Fort Washington Ave, New York, NY 10032 (E-mail: ht2225@ cumc.columbia.edu).

J Thorac Cardiovasc Surg 2022;164:1510-1

$0022-5223 / \$ 36.00$

Copyright (c) 2020 by The American Association for Thoracic Surgery

https://doi.org/10.1016/j.jtcvs.2020.10.082
}

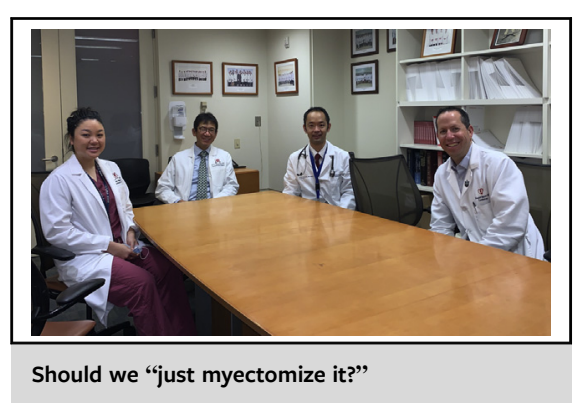

CENTRAL MESSAGE

Mayo Clinic data show a survival

advantage with early SRT over

medical management, shedding

light on the optimal timing of

SRT in obstructive HCM.

symptoms and quality of life. In fact, even delayed SRT was shown to have a survival benefit over medical management. Additionally, early SRT yielded a survival advantage in female patients, those in New York Heart Association functional class III and IV, and nondiabetic patients. Prior data indicate that women with HCM generally tend to be older and more symptomatic at presentation compared with men. ${ }^{5}$ Therefore, the early SRT strategy for women and the benefit of that approach observed in this study may avoid worse clinical outcomes because women likely have greater diastolic dysfunction and more advanced cardiac remodeling at the time of referral.

Procedure mortality is $1 \%$ or less in recent studies for both interventions at experienced centers. ${ }^{6}$ With advances in management and improvement in technique, the authors appropriately question whether the benefits of watchful waiting outweigh the risks of SRT. This is particularly important in minimally symptomatic patients, because the presence of significant left ventricular outflow tract obstruction adversely affects outcomes, irrespective of symptoms, and has been shown to be a predictor of mortality in this subset. ${ }^{7}$ Overall, a reiteration of the current guidelines favoring earlier SRT may be warranted to mitigate the known time-dependent risks of obstructive HCM.

Although external validity of the findings from a tertiary referral center with extremely high volume may be limited and additional confirmatory evidence from outside of the Mayo Clinic is warranted, ${ }^{8}$ we trust that our colleagues at the Mayo Clinic, who have already contributed so much to the field on this topic, will continue to 
spearhead the pursuit to optimize management in this heterogeneous disease.

\section{References}

1. Cui H, Schaff HV, Geske JB, Lahr BD, Dearani JA, Nishimura RA, et al. Early septal reduction therapy for patients with obstructive hypertrophic cardiomyopathy. J Thorac Cardiovasc Surg. 2022;164:1502-9.e5.

2. American College of Cardiology Foundation/American Heart Association Task Force on Practice, American Association for Thoracic Surgery, American Society of Echocardiography, American Society of Nuclear Cardiology, Heart Failure Society of America, Heart Rhythm Society, et al. 2011 ACCF/AHA guideline for the diagnosis and treatment of hypertrophic cardiomyopathy: a report of the American College of Cardiology Foundation/American Heart Association task force on practice guidelines. J Thorac Cardiovasc Surg. 2011;142:e153-203.

3. Authors/Task Force Members, Elliott PM, Anastasakis A, Borger MA, Borggrefe M, Cecchi F, et al. 2014 ESC guidelines on diagnosis and management of hypertrophic cardiomyopathy: the task force for the diagnosis and management of hypertrophic cardiomyopathy of the European Society of Cardiology (ESC) Eur Heart J. 2014;35:2733-79.

4. Cavigli L, Fumagalli C, Maurizi N, Rossi A, Arretini A, Targetti M, et al. Timing of invasive septal reduction therapies and outcome of patients with obstructive hypertrophic cardiomyopathy. Int J Cardiol. 2018;273:155-61.

5. Huurman R, Schinkel AFL, de Jong PL, van Slegtenhorst MA, Hirsch A, Michels M, et al. Impact of sex on timing and clinical outcome of septal myectomy for obstructive hypertrophic cardiomyopathy. Int J Cardiol. August 22, 2020 [Epub ahead of print].

6. Maron BJ, Dearani JA, Ommen SR, Maron MS, Schaff HV, Nishimura RA, et al Low operative mortality achieved with surgical septal myectomy: role of dedicated hypertrophic cardiomyopathy centers in the management of dynamic subaortic obstruction. J Am Coll Cardiol. 2015;66:1307-8.

7. Sorajja P, Nishimura RA, Gersh BJ, Dearani JA, Hodge DO, Wiste HJ, et al. Outcome of mildly symptomatic or asymptomatic obstructive hypertrophic cardiomyopathy: a long-term follow-up study. J Am Coll Cardiol. 2009;54:234-41.

8. Meng X, Liang M, Shi Y, Zhou S, Zhang W, Gao C. Effects of surgical septa myectomy on survival in patients with hypertrophic obstructive cardiomyopathy. Anatol J Cardiol. 2020;23:342-8.

\section{Commentary: Invasive therapy for hypertrophic obstructive cardiomyopathy: Is it time to reexamine the guidelines?}

\author{
Amine Mazine, MD, MSc, Derrick Y. Tam, MD, PhD, \\ and Stephen E. Fremes, MD, MSc
}

Hypertrophic obstructive cardiomyopathy (HOCM) is associated with reduced life expectancy and quality of life, ${ }^{1,2}$ even in asymptomatic or mildly symptomatic patients. ${ }^{3}$ Previous observational studies have shown that septal reduction therapy (SRT) in the form of surgical septal myectomy restores long-term survival in HOCM patients to that of the age- and sex-matched general population. ${ }^{4}$ Nonetheless, both European and American practice

\footnotetext{
From the Division of Cardiac Surgery, Schulich Heart Centre, Department of Surgery, Sunnybrook Health Sciences Centre, University of Toronto, Toronto, Ontario, Canada. Disclosures: The authors reported no conflicts of interest.

The Journal policy requires editors and reviewers to disclose conflicts of interest and to decline handling or reviewing manuscripts for which they may have a conflict of interest. The editors and reviewers of this article have no conflicts of interest.

Received for publication Nov 2, 2020; revisions received Nov 2, 2020; accepted for publication Nov 3, 2020; available ahead of print Nov 7, 2020.

Address for reprints: Stephen E. Fremes, MD, MSc, Dr Bernard S. Goldman Chair in Cardiovascular Surgery, Schulich Heart Centre, Sunnybrook Health Sciences Centre, 2075 Bayview Ave, Room H4 05, Toronto, ON, Canada M4N 3M5 (E-mail: Stephen.fremes@sunnybrook.ca).

J Thorac Cardiovasc Surg 2022;164:1511-3 0022-5223/ $\$ 36.00$

Copyright (c) 2020 Published by Elsevier Inc. on behalf of The American Association for Thoracic Surgery

https://doi.org/10.1016/j.jtcvs.2020.11.008
}

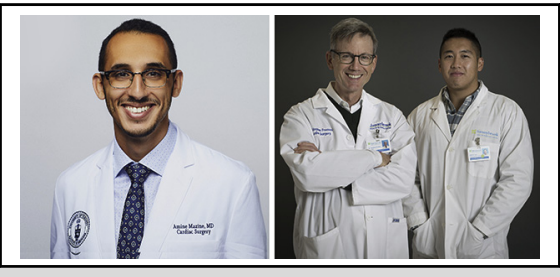

Amine Mazine, MD, MSc, Stephen E. Fremes, MD, MSc, and Derrick Y. Tam, MD, PhD

CENTRAL MESSAGE
In experienced centers, early
septal reduction therapy is
associated with improved
long-term survival in women and
symptomatic patients with
hypertrophic obstructive
cardiomyopathy.

guidelines recommend that SRT be reserved for patients whose symptoms are refractory to medical treatment (class $\mathrm{I}$; level of evidence, $\mathrm{B}$ in European guidelines and $\mathrm{C}$ in American guidelines). ${ }^{5,6}$ Furthermore, there remains a paucity of data to guide the optimal timing of invasive treatment of patients with HOCM.

In this issue of the Journal, Cui and colleagues ${ }^{7}$ attempt to address this gap in knowledge and challenge the existing paradigm of treating only those with refractory symptoms. This article represents another important contribution from the Mayo Clinic on the treatment of HOCM. In this 